\title{
INVESTMENT, UNCERTAINTY, AND PRODUCTION GAMES
}

\author{
SJUR DIDRIK FLAM \\ YURI ERMOLIEV
}

\section{CESIFO WORKING PAPER NO. 1191}

CATEGORY 8: RESOURCES AND ENVIRONMENT

MAY 2004

CESifo Area Conference On INDUSTRIAL ORganisation, MARCH 2004

\footnotetext{
An electronic version of the paper may be downloaded

- from the SSRN website:

- from the CESifo website:

www.SSRN.com

www.CESifo.de
} 


\title{
INVESTMENT, UNCERTAINTY, AND PRODUCTION GAMES
}

\begin{abstract}
This paper explores some cooperative aspects of investments in uncertain, real options. Key production factors are assumed transferable. They may reflect property or user rights. Emission of pollutants and harvest of renewable resources are cases in point. Of particular interest are alternative projects or technologies that provide inferior but anti-correlated returns. Any such project stabilizes the aggregate proceeds. Therefore, given widespread risk exposure and aversion, that project's worth may embody an extra bonus. The setting is formalized as a stochastic production game. Granted no economies of scale such games are quite tractable in analysis, computation, and realization. A core imputation comes in terms of contingent shadow prices that equilibrate competitive, endogenous markets. The said prices emerge as optimal dual solutions to coordinated production programs, featuring pooled resources - and also via adaptive procedures. Extra value - or an insurance premium - adds to any project whose yield is negatively associated with the aggregate.
\end{abstract}

JEL classification: C71.

Keywords: investment, risk attitudes, insurance, covariance-pricing, cooperative games, core, stochastic optimization.

Sjur Didrik Flåm

University of Bergen

Department of Economics

Fosswinckels Gatan 6

5007 Bergen

Norway

sjur.flaam@econ.uib.no
Yuri Ermoliev

International Institute for Applied Systems

Analysis (IIASA)

A-2361 Laxenburg

Austria

ermoliev@iiasa.ac.at 


\section{INTRODUCTION}

The actual management of natural resources and ecosystems inspires great concerns with sustainability and welfare. Notably, the possible depletion of shared stocks, and the emission of harmful pollutants into commons, gives rise to legitimate worries about efficiency and equity.

Typically the related industries must make heavy investments ex ante that cannot easily be undone or recouped ex post. Also, net returns may be rather uncertain in magnitude and somewhat distant in time. ${ }^{1}$ Together these facts beg for thorough investment analysis, emphasizing precaution and the value of keeping options alive.

For such analysis, presuming relevant data, several disciplines have much to offer. First, and maybe foremost, comes economics of finance and insurance. Second, since one cannot avoid computation altogether, there is, in principle, no escape from optimization theory. Third, and somewhat surprisingly, since exchanges may be implicit or lurking in the background, so-called production (or market) games can elucidate multi-agent interaction.

It is seldom though, to find all these ingredients in one and the same study. Most analysts contend with the restricted perspective (and the partial analysis) that

\footnotetext{
${ }^{1}$ Important references include [1], [2], [6], [7], [8], and [17].
} 
suits a single agent, situated within well defined markets. Easily ignored then is the endogenous nature of allocations and prices. Also troublesome is the possible absence of markets for inputs, products or risks. Such absence greatly affects the willingness to invest in large-scale projects, promising fairly unpredictable and "belated" dividends.

This paper deals with projects of precisely that sort. Besides, it accommodates many agents, each acting in three roles: as consumer, investor and producer. At the outset each owns a separate project, offering him uncertain returns. Our main purpose is to "compute" the total and marginal value of investing in those projects. As will become clear, such values are interdependent, subject to contingencies, and determined endogenously. Especially interesting are projects whose net returns swing "out-of-phase" with the aggregate. Their yield is "up" precisely when the total proceeds are "down". That convenient feature confers extra mark-ups on their values.

Technologies of such "counter-cyclical" sort abound, but they tend to cost more. Examples include:

- selective gears for harvesting multi-species, multi-cohort fish stocks;

- diversification over crops and livestock, and ecological production in agriculture;

- electricity production based on wind, biomass or solar energy.

In each case the alternative technology is costlier to operate, but it better safeguards the environment.

For more concrete examples consider two arrangements for electricity generation. In the first, suppose all plants are driven by hydro-power. Some depend on highly correlated, short term precipitation; they are well furnished in chilly, wet years. Other, more expensive plants merely tap melting water under a glacier; they are best off in warm, dry years. Given aggregate supply commitments, the two groups can mutually insure each other. Such insurance ex post affects investments ex ante. In the second arrangement, suppose the base load be delivered by thermal/nuclear plants. Hydro-power then acts only as swing producer; it serves peak demand and receives a marked-up price. Again, prudent investments will be affected throughout the sector.

To study such features Section 2 introduces the prototypical agent. Section 3 places several of them into a two-stage, cooperative setting, affected by much uncertainty. Brought out there are core solutions ex ante and ex post, both determined by shadow prices. Section 4 offers some novel qualitative results, akin to covariancepricing in finance. Section 5 illustrates a few insights about parallel projects, and Section 6 briefly discusses comparative risk advantages. Section 7 considers attainment of equilibrium in environmental games, and Section 8 concludes.

This paper addresses at least three types of readers. Included are first, economists, not quite aware of the rich opportunities production games offer, be it in positive or normative way; second, finance/insurance analysts, little concerned with Lagrangian duality; and finally, optimizers, not fully conversant with the cooperative aspects of such duality. 


\section{The Risk-Exposed Agent}

Considered here is a prototypical agent, being at once consumer, investor, and producer. His decisions evolve step-wise as described next:

Right now install capacity or capital $k$.

$\leadsto$ Next, observe the state $\omega \in \Omega$ and a contingent resource endowment $e(\omega)$.

$\leadsto$ Thereafter, adjust the capital stock by $\Delta k$ and acquire resources $r$.

$\leadsto$ Go on to produce output $f(k, \omega, \Delta k, r)$.

$\leadsto$ Finally, consume $c$ and collect payoff $\pi(k, \omega, \Delta k, r, c)$.

Often $k \leq \bar{k}$ where the prescribed upper bound $\bar{k}$ reflects natural limits or some historical right bestowed on the agent at hand. Examples are manifold. The table below indicates some instances:

$\left[\begin{array}{llll}\text { sector }: & \text { choice } k: & \underline{\text { threshold }} \bar{k}: & \underline{\text { uncertain }} \omega \text { or } e(\omega) \\ \text { hydropower } & \text { water reservoir } & \text { environmental limit } & \text { precipitation } \\ \text { fisheries } & \text { catch capacity } & \text { historical right } & \text { stock abundance } \\ \text { pollution } & \text { abatement capacity } & \text { target level } & \text { nature's tolerance } \\ \text { agriculture } & \text { density of lifestock } & \text { regulation } & \text { disease/pest }\end{array}\right]$

In any case, the realization $\omega$ remains unknown at the time when $k$ is chosen. By contrast, $\Delta k, r, c$ are contingent decisions; that is, they depend on the pair $(k, \omega)$.

At this point two modelling issues come up. The first concerns dimensionality, the second uncertainty. Regarding the first, we may easily accommodate several sorts of capacities, resources and products, increasing thereby the dimension of the decision spaces. Doing so entails, in principle, no additional cost, be it in analysis or presentation (albeit of course in computation). ${ }^{2}$ In fact, the reader may choose freely whether to regard some items as vectors or real numbers. For intuition it simplifies though, to deal merely with one-dimensional spaces. ${ }^{3}$

The second modelling issue concerns perception of risk and uncertainty. This bears of course on what is known, unknown and unknowable [16]. We take a "simplistic" stand here, assuming that uncertainty amounts (and reduces) to a probabilistic description of possible $\omega$-values. Then, at one extreme end, one may posit that the probability distribution of $\omega$ be known by each and every concerned party. This hypothesis is certainly convenient, but hardly realistic. So, in lack of such knowledge, at the other extreme (and decisively more realistic) end, one may have to contend with sequential realizations of $\omega$, and the attending build-up of empirical statistics.

\footnotetext{
${ }^{2}$ Indeed, when $k, \bar{k}$ are vectors in the same space, $c$ reside in another linear space, and $r$ maybe in a third, corresponding vector inequalities should be understood to hold componentwise. And, juxtaposition of two compatible vectors then implies that the standard inner product be executed.

${ }^{3}$ In extremis, one may read this paper as dealing merely with financial markets.
} 
We shall deal with both scenarios. In either case, $E$ denotes the expectation operator with respect to $\omega$. To bypass purely technical concerns with measurability and integrability, assume $\Omega$ finite. Also, attainment of extremal values is tacitly assumed.

While still facing uncertainty, the agent wants to maximize the expectation of his payoff $\pi(k, \omega, \Delta k, r, c)$. If operating in autarchy, isolated from others, he should

maximize $E \pi(k, \omega, \Delta k, r, c)$ subject to $k \leq \bar{k}, r \leq e(\omega), c \leq f(k, \omega, \Delta k, r)$.

Here and elsewhere we do not mention evident sign restrictions like $k, r, c \geq 0$. Note that problem (1) has two stages. First, $k$ must be sunk before knowing $\omega$. Second, after $\omega$ and $e(\omega)$ are unveiled, the decision maker had better

$$
\text { maximize } \pi(k, \omega, \Delta k, r, c) \text { subject to } r \leq e(\omega) \text { and } c \leq f(k, \omega, \Delta k, r) \text {. }
$$

Several sorts of uncertainty may prevail, be it in preferences, productivity, or resource abundance. Format (1) is generic and quite general, able to accommodate manifold instances. In particular, if capital adjustment comes at prohibitive cost, $\Delta k$ is not mentioned. Similarly, when $e$ is missing, $r$ should be omitted.

Admittedly, for realistic analysis, the planning horizon should extend beyond two stages. It had better do so partly, because uncertainty is unveiled gradually, over many steps - and partly, because there are repeated opportunities to take recourse actions. Such complexity notwithstanding, if one is willing to work in suitably high dimensions, problem format (1) is rich enough to comprise as many stages and commodities as deemed necessary; see [12]. For our purpose it suffices to think of all future intervals as compressed into a single second period. Doing so simplifies things, and more so when several agents come on stage simultaneously - as described in the next section. The short time horizon seems particularly appropriate there because agents, who face substantial uncertainty, hesitate to make more than limited contractual commitments into the future.

\section{Stochastic Production Games}

Accommodated henceforth is a fixed, finite set $I$ of agents, each of the prototypical sort just described. Agent $i \in I$ proceeds step-wise, in the following order: First, he installs capacity $k_{i}$. Next, he observes $\omega$ and $e_{i}(\omega)$. Thereafter, he makes capital adjustment $\Delta k_{i}$, uses resource $r_{i}$, and produces output $f_{i}\left(k_{i}, \omega, \Delta k_{i}, r_{i}\right)$. Finally, it is time for him to consume $c_{i}$ and collect payoff $\pi_{i}\left(k_{i}, \omega, \Delta k_{i}, r_{i}, c_{i}\right)$.

The interaction among several such agents is modelled next by various cooperative games. Each such game associates a real value $V_{S}$ to every coalition $S \subseteq I$. The mapping $S \mapsto V_{S}$ is called the characteristic function of the game in question. A payment scheme $\left(u_{i}\right) \in \mathbb{R}^{I}$ is then said to be in the core iff it entails

Pareto efficiency: $\sum_{i \in I} u_{i}=V_{I}$ and no blocking: $\quad \sum_{i \in S} u_{i} \geq V_{S}$ for all $S \subset I$. 
The efficiency constraint requires that the overall value $V_{I}$ be attained and fully shared. The no blocking constraint captures that a dissatisfied coalition $S$, offered merely $\sum_{i \in S} u_{i}<V_{S}$, would reject that proposal (or defect from the others).

Instead of autarchy, as described in Section 2, suppose now that the agents can trade/exchange inputs and outputs among themselves. If $\mathbf{k}_{S}:=\left(k_{i}\right)_{i \in S}$ and $\omega$ are given at the second stage, then coalition $S$ can achieve ex post value

$$
v_{S}\left(\mathbf{k}_{S}, \omega\right):=\max \left\{\begin{array}{l}
\sum_{i \in S} \pi_{i}\left(k_{i}, \omega, \Delta k_{i}, r_{i}, c_{i}\right) \text { subject to } \\
\sum_{i \in S} r_{i} \leq \sum_{i \in S} e_{i}(\omega), \quad \sum_{i \in S} c_{i} \leq \sum_{i \in S} f_{i}\left(k_{i}, \omega, \Delta k_{i}, r_{i}\right),
\end{array}\right.
$$

maximum taken with respect to $\left(\Delta k_{i}, r_{i}, c_{i}\right)_{i \in S}$. Ex ante the same coalition could shoot for value

$$
v_{S}\left(\bar{k}_{S}\right):=\max \left\{E v_{S}\left(\mathbf{k}_{S}, \omega\right): \sum_{i \in S} k_{i} \leq \sum_{i \in S} \bar{k}_{i}=: \bar{k}_{S}\right\} .
$$

Clearly, these values, be it $V_{S}=v_{S}\left(\mathbf{k}_{S}, \omega\right)$ or $V_{S}=v_{S}\left(\bar{k}_{S}\right)$, are superadditive; that is,

$$
V_{S} \geq V_{\mathbf{S}}+V_{S \backslash \mathbf{s}} \text { whenver } \mathbf{S} \varsubsetneqq S \subseteq I \text {. }
$$

This inequality indicates gains to be had by coordinating investment and consumption. So we ask: Can all cooperative benefits be achieved? If so, in what manner? Can some voluntary contract be instrumental? Is it easy to implement? And how does it affect investment decisions in the first place?

Under some natural, standing assumptions all these questions have positive or constructive answers - as will be brought out next. Those assumptions include that for each $\omega$ the contingent functions $\pi_{i}, f_{i}$ be concave in the other variables, and that each $\pi_{i}$ be increasing in $\left(r_{i}, c_{i}\right)$.

First-stage cooperation (3) anticipates that second-stage cooperation (2) will follow. Such anticipation makes it natural to disentangle one from the other:

Proposition 1. (Ex post contingent core solutions) For the grand coalition $S=I$, given capacity profile $\mathbf{k}:=\left(k_{i}\right)_{i \in I}$ and realization $\omega$, let $\Lambda_{r}(\mathbf{k}, \omega), \Lambda_{c}(\mathbf{k}, \omega)$, be a Lagrange multipliers associated to the first and second constraint in (2). This means that the standard Lagrangian $L(\mathbf{k}, \omega, \Delta \mathbf{k}, \mathbf{r}, \mathbf{c}, \boldsymbol{\lambda}):=$

$$
\sum_{i \in I}\left\{\pi_{i}\left(k_{i}, \omega, \Delta k_{i}, r_{i}, c_{i}\right)+\lambda_{r}\left[e_{i}(\omega)-r_{i}\right]+\lambda_{c}\left[f_{i}\left(k_{i}, \omega, \Delta k_{i}, r_{i}\right)-c_{i}\right]\right\},
$$

after inserting $\boldsymbol{\lambda}:=\left[\lambda_{r}, \lambda_{c}\right]=\left[\Lambda_{r}(\mathbf{k}, \omega), \Lambda_{c}(\mathbf{k}, \omega)\right]$, should satisfy

$$
\max _{\Delta \mathbf{k}, \mathbf{r}, \mathbf{c}} L(\mathbf{k}, \omega, \Delta \mathbf{k}, \mathbf{r}, \mathbf{c}, \boldsymbol{\lambda}) \leq v_{I}\left(\mathbf{k}_{I}, \omega\right) .
$$

If so, the state-dependent payment scheme $u_{i}(\mathbf{k}, \omega):=$

$$
\max _{\Delta k_{i}, r_{i}, c_{i}}\left\{\pi_{i}\left(k_{i}, \omega, \Delta k_{i}, r_{i}, c_{i}\right)+\lambda_{r}(\mathbf{k}, \omega)\left[e_{i}(\omega)-r_{i}\right]+\Lambda_{c}(\mathbf{k}, \omega)\left[f_{i}\left(k_{i}, \omega, \Delta k_{i}, r_{i}\right)-c_{i}\right]\right\}
$$


belongs to the core of the second-stage, contingent game having characteristic function $S \mapsto v_{S}\left(\mathbf{k}_{S}, \omega\right)$, as defined in (2). When $\sum_{i \in I}\left[e_{i}(\omega), f_{i}\left(k_{i}, \omega, 0, e_{i}(\omega)\right)\right]>>0$, there do exist Lagrange multipliers.

Let next

$$
L(\mathbf{k}, \omega, \Delta \mathbf{k}, \mathbf{r}, \mathbf{c}, \boldsymbol{\lambda}, \mu):=L(\mathbf{k}, \omega, \Delta \mathbf{k}, \mathbf{r}, \mathbf{c}, \boldsymbol{\lambda})+\sum_{i \in I} \mu\left(\bar{k}_{i}-k_{i}\right) .
$$

Proposition 2. (Ex ante core solution) For the grand coalition $S=I$, suppose $\omega \mapsto \lambda_{r}(\omega), \lambda_{c}(\omega)$ are Lagrange multiplier profiles associated to the first and second constraint in (2), and that $\mu$ is associated to $\sum_{i \in I} k_{i} \leq \sum_{i \in I} \bar{k}_{i}=: \bar{k}_{I}$. This means that

$$
\max _{\left(k_{i}\right)} E \max _{\Delta \mathbf{k}, \mathbf{r}, \mathbf{c}} L(\mathbf{k}, \omega, \Delta \mathbf{k}, \mathbf{r}, \mathbf{c}, \boldsymbol{\lambda}, \boldsymbol{\mu}) \leq v_{I}\left(\bar{k}_{I}\right) .
$$

Then the payment scheme $U_{i}\left(\bar{k}_{i}, \sum_{j \neq i} \bar{k}_{j}\right):=$

$$
\max _{k_{i}} E \max _{\Delta k_{i}, r_{i}, c_{i}}\left\{\begin{array}{l}
\pi_{i}\left(k_{i}, \omega, \Delta k_{i}, r_{i}, c_{i}\right)+ \\
\lambda_{r}(\omega)\left[e_{i}(\omega)-r_{i}\right]+ \\
\lambda_{c}(\omega)\left[f_{i}\left(k_{i}, \omega, \Delta k_{i}, r_{i}\right)-c_{i}\right]+ \\
\mu\left(\bar{k}_{i}-k_{i}\right)
\end{array}\right\}
$$

constitutes an overall core solution for the game having characteristic function $S \mapsto$ $v_{S}\left(\bar{k}_{S}\right)$, as defined in (3). If $\sum_{i \in I}\left[e_{i}(\omega), f_{i}\left(\bar{k}_{i}, \omega, 0, e_{i}(\omega)\right)\right]>>0$ almost surely, and $\bar{k}_{I}>0$, there do exist Lagrange multipliers $\omega \mapsto \lambda_{r}(\omega), \lambda_{c}(\omega)$ and $\mu$.

One should not be lured into thinking that commonplace multipliers, furnished by necessary optimality conditions for problems (2), (3), automatically generate core imputations via (6). Rather, what imports here is that assumptions (4), (5) have the nature of sufficient optimality conditions. To satisfy these it largely helps to have $\pi_{i}, f_{i}$ concave for each $\omega$.

The above propositions, proven in Appendix, show how agents, having convex preferences and stochastic assets, can pool inputs, outputs and endowments to smoothen and insure individual payoffs across eventualities and time [14]. Individual projects can thus share risks - and occasionally even eliminate them. In particular, this holds when parties are few and risks idiosyncratic, so that neither the law of large numbers nor the Arrow-Lind theorem apply [3]. The main instruments for risk sharing are endogenous prices. These emerge as Lagrange multipliers, and they equilibrate intrinsic markets [22]. At those markets all parties are construed as price-takers.

One may rightly claim that Propositions $1 \& 2$ merely "rediscover" - or, just apply - known welfare properties of competitive equilibrium, stemming from its residence within the core. That viewpoint is certainly useful, but not quite necessary. In fact, Shapley-Shubik's cooperative perspective on market games largely suffices [22]. Important and novel in that perspective is presence of two stages - and associated recourse options, exercised as events unfold. Particularly interesting are differential impacts of uncertainty on various projects. We address that issue next. 


\section{Covariance-Pricing of Projects}

Let $\Delta \hat{k}_{i}, \hat{r}_{i}, \hat{c}_{i}$ denote optimal (so-called recourse) decisions, assumed unique and well defined, in (6). Write briefly $f_{i}\left(k_{i}, \omega\right)$ for $f_{i}\left(k_{i}, \omega, \Delta \hat{k}_{i}, \hat{r}_{i}\right)$. The two terms $\lambda_{r} e_{i}$ and $\lambda_{c} f_{i}\left(k_{i}\right)$ are in focus here. These record the reimbursements to $i$ for his endowment and output respectively. To inquire about the nature of these pecuniary items, recall that two random variables $X, Y$ are declared negatively dependent (or briefly -dependent) if for all values $x, y$

$$
\operatorname{Pr}[X \leq x, Y \leq y] \leq \operatorname{Pr}[X \leq x] \operatorname{Pr}[Y \leq y] .
$$

Equivalently, there is negative dependence if $\operatorname{Pr}[X \leq x \mid Y \leq y] \leq \operatorname{Pr}[X \leq x]$. In short, knowing $Y$ small, reduces the likelihood that $X$ also be small. Positive dependence (briefly +dependence) obtains when $\operatorname{Pr}[X \leq x, Y \leq y] \geq \operatorname{Pr}[X \leq x] \operatorname{Pr}[Y \leq y]$ for all $x, y$.

Proposition 3. (Dependence and covariance [19]) If $X, Y$ are negatively (positively) dependent and $D: \mathbb{R} \rightarrow \mathbb{R}$ is strictly decreasing, then $X, D(Y)$ are oppositely dependent, and the sign of $\operatorname{cov}(X, Y)$ is $-1(+1$ respectively).

The multipliers $\lambda_{r}$ and $\lambda_{c}$ in (6) are random, but depend also on the aggregate endowment $e_{I}$ and output $f_{I}:=\sum_{i \in I} f_{i}$ respectively. Ceteris paribus that dependence shows up as "inverse demand curves" $e_{I} \mapsto \lambda_{r}\left(e_{I}\right), f_{I} \mapsto \lambda_{c}\left(f_{I}\right)$. It is commonplace that such curves be decreasing. Not surprisingly, this property obtains here also:

Proposition 4. (Monotonicity of shadow prices) The inverse demand curves $e_{I} \mapsto$ $\lambda_{r}\left(e_{I}\right), f_{I} \mapsto \lambda_{c}\left(f_{I}\right)$ are both decreasing. That is, almost surely

$$
\begin{gathered}
{\left[e_{I}-\bar{e}_{I}\right]\left[\lambda_{r}\left(e_{I}\right)-\lambda_{r}\left(\bar{e}_{I}\right)\right] \leq 0 \text { whenever } e_{I} \neq \bar{e}_{I} \text {, and }} \\
{\left[f_{I}-\bar{f}_{I}\right]\left[\lambda_{c}\left(f_{I}\right)-\lambda_{c}\left(\bar{f}_{I}\right)\right] \leq 0 \text { whenever } f_{I} \neq \bar{f}_{I} .}
\end{gathered}
$$

Proof. The reduced Lagrangian function $\mathcal{L}(\mathbf{k}, \omega, \boldsymbol{\lambda}):=\max _{\Delta \mathbf{k}, \mathbf{r}, \mathbf{c}} L(\mathbf{k}, \omega, \Delta \mathbf{k}, \mathbf{r}, \mathbf{c}, \boldsymbol{\lambda})$ is concave with respect to $e_{I}$ and $f_{I}$. Consequently, the corresponding partial derivatives $\lambda_{r}=\frac{\partial}{\partial e_{I}} \mathcal{L}(\mathbf{k}, \omega)$ and $\lambda_{c}=\frac{\partial}{\partial f_{I}} \mathcal{L}(\mathbf{k}, \omega)$ are decreasing.

Combining Proposition 3 with strict versions of inequalities (7), (8) we get:

Proposition 5. (Dependence between shadow prices individual supply) Quite naturally suppose that the inverse demand curve $e_{I} \mapsto \lambda_{r}\left(e_{I}\right)$ be strictly decreasing. Then, if $e_{I}, e_{i}$ are one-sided dependent, $\lambda_{r}, e_{i}$ are oppositely dependent. So, if $e_{I}, e_{i}$ are $\mp$ dependent, then $\operatorname{cov}\left(\lambda_{r}, e_{i}\right)$ has opposite sign, whence

$$
E\left[\lambda_{r} e_{i}\right]>(<) E\left[\lambda_{r}\right] E\left[e_{i}\right] .
$$

In finance jargon, $\mp$ dependence between $e_{I}, e_{i}$, confers a " $\beta$-value" on $e_{i}$ of opposite sign. In short $\mp$ dependence, yields a corresponding \pm bonus. 
If $f_{I} \mapsto \lambda_{c}\left(f_{I}\right)$ is strictly decreasing, quite similar statements obtain for $\lambda_{c}$ and $f_{I}$.

If for example, under autarchy, standard present-value calculations proves project $i$ "in the money", but $f_{I}, f_{i}$ are positively dependent, then it better be fairly "deep in the money." Ex ante $k_{i}$ is valued at the margin by the formula

$$
E \frac{\partial}{\partial k_{i}}\left[\pi_{i}\left(k_{i}, \omega, \Delta \hat{k}_{i}, \hat{r}_{i}, \hat{c}_{i}\right)+\lambda_{c}(\omega) f_{i}\left(k_{i}, \omega, \Delta \hat{k}_{i}, \hat{r}_{i}\right)\right]
$$

Enters here, as a separate part, the commonplace covariance format of pricing:

$$
E\left[\lambda_{c} \frac{\partial}{\partial k_{i}} f_{i}\left(k_{i}\right)\right]=E\left[\lambda_{c}\right] E\left[\frac{\partial}{\partial k_{i}} f_{i}\left(k_{i}\right)\right]+\operatorname{cov}\left[\lambda_{c}, \frac{\partial}{\partial k_{i}} f_{i}\left(k_{i}\right)\right] .
$$

5. Parallel Production

For illustration consider now a simple, tractable instance where project $i$ contributes a steady income flow $\varphi_{i}$ over the time interval $\left[0, T_{i}\right]$. Since revenues are discounted continuously at rate $\rho>0$, that project furnishes present value

$$
\varphi_{i} \int_{0}^{T_{i}} e^{-\rho t} d t=\frac{\varphi_{i}}{\rho}\left\{1-e^{-\rho T_{i}}\right\} .
$$

Let $T_{i}:=r_{i} / \varphi_{i}$ where $r_{i} \geq 0$ denotes the amount of resources devoted to project $i$. Consequently, presuming that capacity adjustment be impossible,

$$
f_{i}\left(k_{i}, \omega, r_{i}\right):=\frac{\varphi_{i}}{\rho}\left\{1-\exp \left[-\rho r_{i} / \varphi_{i}\right]\right\}
$$

where $\varphi_{i}=\Phi_{i}\left(k_{i}, \omega\right) \geq 0$. For simple notation write $\varphi_{I}:=\sum_{i \in I} \varphi_{i}$. Also for simplicity, take $\pi_{i}\left(k_{i}, \omega, c_{i}, r_{i}\right)=c_{i}$. Agent $i$ receives endowment $e_{i}(\omega)$ at the second stage, this yielding aggregate $e_{I}:=\sum_{i \in I} e_{i}$. At that stage, given $\mathbf{k}_{S}=\left(k_{i}\right)_{i \in S}$ and $\omega$, coalition $S \subseteq I$ could achieve

$$
v_{S}\left(\mathbf{k}_{S}, \omega\right):=\max _{\left(r_{i}\right)}\left\{\sum_{i \in S} f_{i}\left(k_{i}, \omega, r_{i}\right): \sum_{i \in S} r_{i} \leq \sum_{i \in S} e_{i}(\omega)\right\}
$$

by pooling its members' objectives, technologies, and endowments. Let $\lambda_{r}(\omega) \geq 0$ be the Lagrange multiplier associated to $\sum_{i \in I} r_{i} \leq \sum_{i \in I} e_{i}(\omega)$. This state-dependent shadow price should satisfy

$$
\sum_{i \in I} \max _{r_{i}}\left\{f_{i}\left(k_{i}, \omega, r_{i}\right)+\lambda_{r}(\omega)\left[e_{i}(\omega)-r_{i}\right]\right\} \leq v_{I}(\mathbf{k}, \omega) .
$$

Simple calculations show that $\lambda_{r}=\exp \left(-\rho e_{I} / \varphi_{I}\right)$ hence $\lambda_{r}$ is strictly decreasing in $e_{I}$, and Proposition 5 applies:

- If $e_{I}, e_{i}$ are negatively (positively) dependent, then $\operatorname{cov}\left(\lambda_{r}, e_{i}\right)$ has opposite sign. 
Simple calculations also show that

- the aggregate endowment $e_{I}$ is distributed according to production flows; that is, the optimal

$$
\hat{r}_{i}=\frac{\varphi_{i}}{\varphi_{I}} e_{I}
$$

Agents with relatively large $\varphi_{i}$ will thus take substantial parts of $e_{I}$. Such linear sharing is known from mutual insurance when $\varphi_{i}$ denotes the risk tolerance of agent $i$; see [4], [19], [23]. The advantages of pooling not perfectly correlated risks are evident. In fact, accidentally "starving" agents are helped by more fortunate fellows. The receivers will reciprocate once providence smiles to them. The resulting ex post payment

$$
u_{i}(k, \omega):=\sup _{r_{i}}\left\{f_{i}\left(k_{i}, \omega, r_{i}\right)+\lambda_{r}(\omega)\left[e_{i}(\omega)-r_{i}\right]\right\}
$$

gives the second-stage core solution. This payment has two terms: first, the production part

$$
f_{i}\left(k_{i}, \omega, \hat{r}_{i}\right)=\varphi_{i} \int_{0}^{e_{I} / \varphi_{I}} e^{-\rho t} d t
$$

second, the net financial transfer

$$
\lambda_{r}\left[e_{i}-\hat{r}_{i}\right]=e^{-\rho e_{I} / \varphi_{I}}\left[e_{i}-\frac{\varphi_{i}}{\varphi_{I}} e_{I}\right]
$$

Since these transfers sum to zero, the second-stage, total value equals $\sum_{i \in I} f_{i}\left(k_{i}, \omega, \hat{r}_{i}\right)$. As one might expect,

- the total "cake" increases by cooperation:

$$
\sum_{i \in I} f_{i}\left(k_{i}, \omega, \hat{r}_{i}\right)=\varphi_{I} \int_{0}^{e_{I} / \varphi_{I}} e^{-\rho t} d t>\sum_{i \in I} \varphi_{i} \int_{0}^{e_{i} / \varphi_{i}} e^{-\rho t} d t=\sum_{i \in I} f_{i}\left(k_{i}, \omega, e_{i}\right) .
$$

The last inequality holds for all $\mathbf{k}$ and $\omega$. It stems from $\int_{0}^{T} e^{-\rho t} d t$ being strictly concave in $T$. Therefore, by Jensen's inequality

$$
\frac{1}{\varphi_{I}} \sum_{i \in I} \varphi_{i} \int_{0}^{e_{i} / \varphi_{i}} e^{-\rho t} d t<\int_{0}^{e_{I} / \varphi_{I}} e^{-\rho t} d t
$$

this attesting to the advantage of pooling resources. Uncertainty is likely to enforce this feature, and especially so when all risks are idiosyncratic. To wit, for illustration, - if each individual endowment $e_{i}$ is random, but their sum $e_{I}$ is not, the gains from cooperation are twofold: They stem first, from substitutions and second, from smoothing:

$$
\begin{aligned}
E \sum_{i \in I} f_{i}\left(k_{i}, \omega, \hat{r}_{i}\right) & =\varphi_{I} \int_{0}^{e_{I} / \varphi_{I}} e^{-\rho t} d t=\varphi_{I} \int_{0}^{\sum_{i} E e_{i} / \varphi_{I}} e^{-\rho t} d t \\
& >\sum_{i \in I} \varphi_{i} \int_{0}^{E e_{i} / \varphi_{i}} e^{-\rho t} d t>E \sum_{i \in I} \varphi_{i} \int_{0}^{e_{i} / \varphi_{i}} e^{-\rho t} d t=E \sum_{i \in I} f_{i}\left(k_{i}, \omega, e_{i}\right) .
\end{aligned}
$$




\section{Comparative Risk Advantage}

David Ricardo - studying international trade, scarce resources, and division of labor - demonstrated that trading nations all gain by specializing in goods of comparative advantages [5]. This section takes up a similar issue. Here however, merely one good comes into play. Accordingly, one might expect that production largely and best be undertaken by the most efficient agent. Under uncertainty this need not be so. Indeed, rather inefficient producers may warrant premiums as suppliers of stability and insurance. This feature becomes particularly pronounced when some inefficient party's risk is out of line with others.

To illustrate in a simple setting, assume there is no capacity limit $\left(\bar{k}_{i}=+\infty\right)$, no capacity adjustments $\left(\Delta k_{i}=0\right)$, and no endowment $\left(e_{i}=0\right)$. Also, instead of payoff consider cost $C_{i}:=-\pi_{i}$ with

$$
C_{i}\left(k_{i}, \omega, c_{i}\right)=\kappa_{i} k_{i}+\kappa\left[d_{i}-c_{i}\right]^{+} .
$$

The operator $[r]^{+}:=\max \{0, r\}$ preserves the positive part of the real number $r$. The parameter $d_{i}$ is construed as $i^{\prime}$ s "inelastic demand". If endogenous supply $c_{i}$ falls short of demand $d_{i}$, the residual amount $d_{i}-c_{i}$ must be procured from external sources at unit cost $\kappa$. Let

$$
f_{i}\left(k_{i}, \omega\right)=k_{i} P_{i}^{b_{i}(\omega)}
$$

where the parameter $P_{i} \in(0,1)$ is prescribed, and $b_{i}(\omega) \in\{0,1\}$ is a binomial variable. The latter takes the value 1 with probability $p_{i} \in[0,1)$, leaving then only the proportion $P_{i}$ of $k_{i}$ intact. With complementary probability $\bar{p}_{i}:=1-p_{i}$, all of $k_{i}$ remains productive. Under autarchy agent $i$ will maximize expected cost

$$
E \max _{c_{i}} C_{i}\left(k_{i}, \omega, c_{i}\right)=\kappa_{i} k_{i}+\kappa\left\{p_{i}\left[d_{i}-P_{i} k_{i}\right]^{+}+\bar{p}_{i}\left[d_{i}-k_{i}\right]^{+}\right\}
$$

with respect to $k_{i}$. In that optic his best choice

$$
k_{i}= \begin{cases}0 & \text { if } \kappa_{i}>\kappa\left\{p_{i} P_{i}+\bar{p}_{i}\right\} \\ d_{i} & \text { if } \kappa p_{i} P_{i} \leq \kappa_{i} \leq \kappa\left\{p_{i} P_{i}+\bar{p}_{i}\right\} \\ d_{i} / P_{i} & \text { if } \kappa_{i}<\kappa p_{i} P_{i}\end{cases}
$$

Next open up for cooperation; that is, for free trade. That opening will minimize

$$
F(\mathbf{k}):=\sum_{i \in I} \kappa_{i} k_{i}+\kappa E\left\{\min _{\left(c_{i}\right)} \sum_{i \in I}\left[d_{i}-c_{i}\right]^{+}: \sum_{i \in I} c_{i} \leq \sum_{i \in I} k_{i} P_{i}^{b_{i}(\omega)}\right\}
$$

with respect to $\left(k_{i}\right)$. Equivalently, trade minimizes

$$
\tilde{F}(\mathbf{k}):=\sum_{i \in I} \kappa_{i} k_{i}+\kappa E\left\{\min _{\left(c_{i}\right)}\left[\sum_{i \in I}\left(d_{i}-c_{i}\right)\right]^{+}: \sum_{i \in I} c_{i} \leq \sum_{i \in I} k_{i} P_{i}^{b_{i}(\omega)}\right\} .
$$


Indeed, a minimizing $\left(c_{i}\right)$ in $F(\mathbf{k})$ satisfies $c_{i} \leq d_{i}$ for all $i$, whence $\sum_{i \in I}\left[d_{i}-c_{i}\right]^{+}=$ $\left[\sum_{i \in I}\left(d_{i}-c_{i}\right)\right]^{+}$and $\tilde{F}(\mathbf{k}) \leq F(\mathbf{k})$. Conversely, given a minimizing profile $\left(\tilde{c}_{i}\right)$ in $\tilde{F}(\mathbf{k})$ there exists for each $i$ a $c_{i} \leq d_{i}$ such that $\sum_{i \in I} c_{i}=\sum_{i \in I} \tilde{c}_{i}$. Hence $\left[\sum_{i \in I} d_{i}-\tilde{c}_{i}\right]^{+}=$ $\sum_{i \in I}\left[d_{i}-c_{i}\right]^{+}$so that $F(\mathbf{k}) \leq \tilde{F}(\mathbf{k})$.

For the sake of transparency, suppose finally that there be only two agents. Objective (10) then takes the reduced form

$$
\kappa_{1} k_{1}+\kappa_{2} k_{2}+\kappa E\left[d_{1}+d_{2}-k_{1} P_{1}^{b_{1}(\omega)}-k_{2} P_{2}^{b_{2}(\omega)}\right]^{+} .
$$

We assume $\kappa_{1}<\kappa_{2}<\kappa$ and briefly discuss three cooperative cases next:

1) Absent uncertainty, when $p_{1}=p_{2}=0$, we get $k_{1}=d_{1}+d_{2}$ and $k_{2}=0$. Then, to no surprise, the most efficient agent produces all.

2) Only the efficient agent is at risk; that is, $p_{1}>0, p_{2}=0$, in which case (11) specializes to

$$
\kappa_{1} k_{1}+\kappa_{2} k_{2}+\kappa\left\{p_{1}\left[d_{1}+d_{2}-k_{1} P_{1}-k_{2}\right]^{+}+\bar{p}_{1}\left[d_{1}+d_{2}-k_{1}-k_{2}\right]^{+}\right\} .
$$

Note that when total supply equals $d_{1}+d_{2}$, the expected marginal production costs are $\kappa_{1}-\kappa\left(p_{1} P_{1}+\bar{p}_{1}\right)$ for agent 1 and $\kappa_{2}-\kappa$ for agent 2 . If the latter is smaller, then, somewhat surprisingly, the cost efficient agent better be inactive, leaving production entirely to his high-cost associate (i.e. $k_{1}=0, k_{2}=d_{1}+d_{2}$ ). The latter is able to compensate qua insurer for his own handicaps qua producer.

3) Both are risk exposed, but in perfectly opposed manner; that is, $p_{1}>0, p_{2}=1-p_{1}$, and $b_{1}(\omega)+b_{2}(\omega)=1$. Then (11) reads

$$
\kappa_{1} k_{1}+\kappa_{2} k_{2}+\kappa\left\{p_{1}\left[d_{1}+d_{2}-k_{1} P_{1}-k_{2}\right]^{+}+p_{2}\left[d_{1}+d_{2}-k_{1}-k_{2} P_{2}\right]^{+}\right\}
$$

The structure of the optimal solution is similar to the preceding case, but outside procurement could become more attractive. In particular, if $\kappa_{1}>\kappa\left(p_{1} P_{1}+\bar{p}_{1}\right)$ and $\kappa_{2}>\kappa\left(p_{2} P_{2}+\bar{p}_{2}\right)$, it is not worth anyone's while to produce.

Nonsmooth objectives like (9), reflecting "hit-or-miss" situations, inspire new measures of risk, notably so-called Conditional Value-at-Risk [21].

\section{Environmental Games and Quota Trade}

As noted, the core imputation (6) reduces essentially to competitive equilibrium in endogenous markets for capital and contingent commodities. One can hardly presume that human-like players, holding imperfect information/competence, will reach such equilibrium right away. More realistically, they must adapt and learn. The classical branch of economics that deals with competitive markets, fails however, to account for necessary adaptation and learning.

The simplicity of our setting invites reconsideration of these matters. But first it is time to address a related question, already invoked, namely: to what extent is 
uncertainty described or formalized? At this point the necessary prerequisites are few and reasonable. To wit, suppose a discrete-time process $\omega^{t}, t=0,1, \ldots$ of independent random variates, all distributed as the underlying $\omega$, can be simulated or observed step by step. Then, since endowments and outputs are fixed ex post - and since income effects are negligible or ignored - there should be good prospects for reaching a stable equilibrium over time. Indeed, recent studies explore the convergence of repeated, bilateral exchange towards an efficient steady state [9], [10], [11], [15].

At this point the only coupling constraint $k_{I}:=\sum_{i \in I} k_{i} \leq \sum_{i \in I} \bar{k}_{i}=: \bar{k}_{I}$ becomes crucial. Suppose that $\bar{k}_{I}$ reflects an aggregate upper bound on the catch of valuable fish, say - or on the emission of greenhouse gases. Hence $k_{I}=\bar{k}_{I}$ holds throughout, and payoffs $\pi_{i}\left(\bar{k}_{I}, \cdot\right)$ could depend on $\bar{k}_{I}$.

An environmental game thus unfolds in which players trade quotas ex ante and contingent commodities ex post. While adjustment of quotas is sluggish, the other variables are easily and quickly changed. So, to simplify, suppose that secondstage markets clear "instantaneously," and that $\Delta k_{i}=0$ there. As a by-product this clearing generates Lagrange multipliers $\lambda_{c}(\omega)$. It also gives reduced functions $\pi_{i}\left(k_{i}, \omega\right):=\pi_{i}\left(k_{i}, \omega, \hat{r}_{i}, \hat{c}_{i}\right)$ and $f_{i}\left(k_{i}, \omega\right):=f_{i}\left(k_{i}, \omega, \hat{r}_{i}, \hat{c}_{i}\right)$. Let $s_{t}>0$ be a sequence of step sizes selected a priori subject to

$$
\sum_{t=0}^{\infty} s_{t}=+\infty, \quad \sum_{t=0}^{\infty} s_{t}^{2}<+\infty
$$

Begin at time $t=0$, with $s=s_{0}, \omega=\omega^{0}, k_{i}=\bar{k}_{i}$, and select two agents $i, j \in I$ at random. From there on the process could evolve iteratively as follows:

- The two agents hold stocks $k_{i}$ and $k_{j}$, respectively. Calculate their realized marginal returns on capital:

$$
m_{i}:=\frac{\partial}{\partial k_{i}}\left[\pi_{i}\left(k_{i}, \omega\right)+\lambda_{c}(\omega) f_{i}\left(k_{i}, \omega\right)\right], \quad m_{j}:=\frac{\partial}{\partial k_{j}}\left[\pi_{j}\left(k_{j}, \omega\right)+\lambda_{c}(\omega) f_{j}\left(k_{j}, \omega\right)\right] .
$$

Transfer $s\left(m_{i}-m_{j}\right)$ to $i$ from $j$, this giving the two parties new holdings:

$$
k_{i} \leftarrow k_{i}+s\left(m_{i}-m_{j}\right) \quad \text { and } \quad k_{j} \leftarrow k_{j}+s\left(m_{j}-m_{i}\right)
$$

- Increase time $t$ by 1 , update $s \leftarrow s_{t}$, and observe a new independent $\omega \leftarrow \omega^{t}$.

- Continue to pick pairs of agents until convergence.

Convergence obtains as in [9], [10], [15]. Note that trade is voluntary and driven by perceived prospects for mutual improvements. It happens out of equilibrium, uses money as instrument, and requires no private information to be revealed. While still away from equilibrium, the price - and the associated monetary compensation - that goes along with a bilateral exchange, could result from bargaining. If so, it would be hard to predict, but depend on the difference, as reflected in $m_{i}-m_{i}$, between $i^{\prime}$ s willingness to buy and sell [18]. 


\section{Concluding Remarks}

While the preceding model were expressly stylized, less telescopic extensions can easily incorporate much realism and detail. But any simple, reasonable version already brings out that stochastic production (or market) games offer manifold opportunities to put much of economic theory, applied mathematics, and computer science jointly to good use. A fortiori this holds in market-like settings, much affected by sequential decisions and uncertainty, not fully grasped by a glimpse in the rear-view mirror. Several theories, and attending practices, then come on stage simultaneously. And they supplement each other. Included are finance, insurance, stochastic optimization and Mont Carlo simulation. These disciplines have complementary concerns and perspectives. Together they facilitate a rich analysis - be it positive or normative - of how players would/should fare. Particularly important is absence or incompleteness of markets. Internal exchanges, of perfectly Walrasian sort, may then provide some mitigation. Presence of public goods/bads - or widespread externalities - need not preclude coordination and relative efficiency. Troublesome though, are economies of scale in which case Lagrange multipliers may not exist [12].

Especially important are concerns with expandability and reversibility of capacity choice [1], [2], [6], [7], [8], [17]. Such concerns could also be studied within the frames of stochastic production games. In particular, those games allow estimates of the value of perfect information [20].

\section{APPENDIX}

Proof of Proposition 1: Recall that any bivariate, real-valued function $\mathbb{L}(\boldsymbol{\xi}, \boldsymbol{\lambda})$ satisfies

$$
\min _{\boldsymbol{\lambda}} \max _{\boldsymbol{\xi}} \mathbb{L}(\boldsymbol{\xi}, \boldsymbol{\lambda}) \geq \max _{\boldsymbol{\xi}} \min _{\boldsymbol{\lambda}} \mathbb{L}(\boldsymbol{\xi}, \boldsymbol{\lambda}) .
$$

(This inequality, named weak duality in optimization theory, reflects the last-mover advantage in zero-sum, two-person, noncooperative games.) In the present context, at the second stage, given $\mathbf{k}=\left(k_{i}\right)$ and $\omega$, let $\boldsymbol{\xi}:=\left(\Delta k_{i}, r_{i}, c_{i}\right)_{i \in S}$, and associate the contingent Lagrangian

$$
L_{S}(\boldsymbol{\xi}, \boldsymbol{\lambda}):=\sum_{i \in S}\left\{\pi_{i}\left(k_{i}, \omega, \Delta k_{i}, r_{i}, c_{i}\right)+\lambda_{r}\left[e_{i}(\omega)-r_{i}\right]+\lambda_{c}\left[f_{i}\left(k_{i}, \omega, \Delta k_{i}, r_{i}\right)-c_{i}\right]\right\}
$$

to coalition $S$. Note that

$$
\min _{\boldsymbol{\lambda} \geq \mathbf{0}} L_{S}(\boldsymbol{\xi}, \boldsymbol{\lambda})=\sum_{i \in S} \pi_{i}\left(k_{i}, \omega, \Delta k_{i}, r_{i}, c_{i}\right)
$$

if $\sum_{i \in S} r_{i} \leq \sum_{i \in S} e_{i}(\omega) \& \sum_{i \in S} c_{i} \leq \sum_{i \in S} f_{i}\left(k_{i}, \omega, \Delta k_{i}, r_{i}\right)$; otherwise the minimal value equals $-\infty$. Consequently,

$$
\max _{\boldsymbol{\xi}} \min _{\boldsymbol{\lambda} \geq \mathbf{0}} L_{S}(\boldsymbol{\xi}, \boldsymbol{\lambda})=v_{S}\left(\mathbf{k}_{S}, \omega\right)
$$


When $\Lambda \geq 0$ is a Lagrange multiplier, coalition $S$ will not block the proposed payment scheme because

$$
\sum_{i \in S} u_{i}(\mathbf{k}, \omega)=\max _{\boldsymbol{\xi}} L_{S}(\boldsymbol{\xi}, \boldsymbol{\Lambda}) \geq \min _{\boldsymbol{\lambda} \geq \mathbf{0}} \max _{\boldsymbol{\xi}} L_{S}(\boldsymbol{\xi}, \boldsymbol{\lambda}) \geq \max _{\boldsymbol{\xi}} \min _{\boldsymbol{\lambda} \geq \mathbf{0}} L_{S}(\boldsymbol{\xi}, \boldsymbol{\lambda})=v_{S}\left(\mathbf{k}_{S}, \omega\right) .
$$

In particular, $\sum_{i \in I} u_{i}(\mathbf{k}, \omega) \geq v_{I}(\mathbf{k}, \omega)$. Since the converse inequality holds by assumption, Pareto efficiency also obtains. When $e_{I}(\omega)$ and $\sum_{i \in I} f_{i}\left(k_{i}, \omega, 0, e_{i}(\omega)\right)$ are both positive, the Slater condition holds - hence existence of multipliers is ensured.

Proof of Proposition 2: Associate here another Lagrangian $\mathcal{L}_{S}:=$

$$
\sum_{i \in S}\left\{\pi_{i}\left(k_{i}, \omega, \Delta k_{i}, r_{i}, c_{i}\right)+\lambda_{r}\left[e_{i}(\omega)-r_{i}\right]+\lambda_{c}\left[f_{i}\left(k_{i}, \omega, \Delta k_{i}, r_{i}\right)-c_{i}\right]+\mu\left(\bar{k}_{i}-k_{i}\right)\right\}
$$

to coalition $S$. Note that

$$
\min _{\mu \geq 0} E \min _{\boldsymbol{\lambda} \geq \mathbf{0}} \mathcal{L}_{S}=E \sum_{i \in S} \pi_{i}\left(k_{i}, \omega, \Delta k_{i}, r_{i}, c_{i}\right)
$$

if $\sum_{i \in \underline{S}} r_{i} \leq \sum_{i \in S} e_{i}(\omega) \& \sum_{i \in S} c_{i} \leq \sum_{i \in S} f_{i}\left(k_{i}, \omega, \Delta k_{i}, r_{i}\right)$ almost surely, and $\sum_{i \in S} k_{i} \leq$ $\sum_{i \in S} \bar{k}_{i}$; otherwise the minimal expected value equals $-\infty$. Consequently, still writing $\boldsymbol{\xi}=\left(\Delta k_{i}, r_{i}, c_{i}\right)_{i \in S}$,

$$
\max _{\mathbf{k}} \min _{\mu \geq 0} E \max _{\xi} \min _{\boldsymbol{\lambda} \geq \mathbf{0}} \mathcal{L}_{S}=v_{S}\left(\bar{k}_{S}\right) .
$$

When $\hat{\lambda}, \hat{\mu}$ are Lagrange multipliers, coalition $S$ will not block the proposed payment scheme $\left(U_{i}\right)$ because $\sum_{i \in S} U_{i}=$

$\max _{\mathbf{k}} E \max _{\boldsymbol{\xi}} \mathcal{L}_{S}(\hat{\lambda}, \hat{\mu}) \geq \min _{\mu} \max _{\mathbf{k}} E \min _{\boldsymbol{\lambda}} \max _{\boldsymbol{\xi}} \mathcal{L}_{S}(\boldsymbol{\lambda}, \boldsymbol{\mu}) \geq \max _{\mathbf{k}} \min _{\mu} E \max _{\boldsymbol{\xi}} \min _{\boldsymbol{\lambda}} \mathcal{L}_{S}=v_{S}\left(\bar{k}_{S}\right)$.

In particular, $\sum_{i \in I} U_{i} \geq v_{I}\left(\bar{k}_{I}\right)$. Since the converse inequality holds by assumption, Pareto efficiency again obtains. The presumed positivity guarantees that the Slater condition holds.

\section{REFERENCES}

[1] A. B. Abel, A. K. Dixit, J. C. Eberly and R. S. Pindyck, Options, the value of capital, and investment, The Quarterly Journal of Economics CXI, 3, 753-777 (1996).

[2] K. J. Arrow and A. C. Fisher, Environmental preservation, uncertainty, and irreversibility, The Quarterly Journal of Economics 88, 312-319 (1974).

[3] K. J. Arrow and R. C. Lind, Uncertainty and the evaluation of public investment decisions, American Economic Review 60, 364-378 (1970).

[4] K. H. Borch, The Economics of Uncertainty, Princeton University Press, New Jersey (1968). 
[5] A. Dixit and V. Normann, Theory of International Trade, Cambridge Univ. Press (1982).

[6] A. Dixit and R. S. Pindyck, Investment under Uncertainty, Second Printing, Princeton University Press (1996).

[7] A. Dixit, R. S. Pindyck and S. Sødal, A markup interpretation of optimal investment rules, The Economic Journal 109, 179-189 (1999).

[8] A. K. Dixit and R. S. Pindyck, Expandability, reversibility, and optimal capacity choice, in M. J. Brennan and L. Trigeorgis, Project Flexibility, Agency, and Competition: New Developments in the Theory and Application of Real Options, Oxford Univ. Press, New York, 50-70 (2000).

[9] Y. Ermoliev, G. Klaassen, and A. Nentjes, Adaptive cost-effective ambient charges under incomplete information, J. Environmental Economics and Management 31, 3748 (1996).

[10] Y. Ermoliev, M. Michalevich, and A. Nentjes, Markets for tradeable emission and ambient permits: A dynamic approach, Environmental and Resource Economics 15, 29-56 (2000).

[11] Y. Ermoliev, M.A. Keyzer and V. Norkin, Global convergence of the stochastic tâtonnement process, Journal of Mathematical Economics 34, 173-90 (2000).

[12] I. V. Evstigneev and S. D. Flåm, Stochastic programming: nonanticipativity and Lagrange multipliers, in Encyclopedia of Optimization, Kluwer (2001).

[13] I. V. Evstigneev and S. D. Flåm, Sharing nonconvex cost, J. Global Optimization 20, 257-271 (2001).

[14] S. D. Flåm, Stochastic programming, cooperation and risk exchange, Optimization Methods and Software 17, 493-504 (2002).

[15] S. D. Flåm, Market clearing and price formation, Typescript (2003).

[16] R. E. Gomory, The known, the unknown and the unknowable, Scientific American 88, June (1995).

[17] C. Henry, The investment decision under uncertainty: the irreversibility effect, The American Economic Review 1006-1012 (1974).

[18] C. D. Kolstad and R. M. Guzman, Information and the divergence between willingness to accept and willingness to pay, J. Environmental Economics and Management 38, 66-80 (1999).

[19] M. Magill and M. Quinzii, Theory of Incomplete Markets, MIT Press, Cambridge, Mass. (1996). 
[20] G. Ch. Pflug, The value of perfect information as a risk measure, in K. Marti, Y. Ermoliev, C. Pflug, Dynamic Stochastic Optimization, Lecture Notes in Economics and Mathematical Systems 532, Springer 275-291 (2004).

[21] R. T. Rockafellar and S. Uryasev, Optimization of Conditional Value-at-Risk, Journal of Risk 2, 21-41 (2000).

[22] L. S. Shapley and M. Shubik, On market games, J. Economic Theory 1, 9-25 (1969).

[23] R. Wilson, The theory of syndicates, Econometrica 36, 119-132 (1968). 


\section{CESifo Working Paper Series}

(for full list see www.cesifo.de)

1124 Chang Woon Nam and Doina Maria Radulescu, Does Debt Maturity Matter for Investment Decisions?, February 2004

1125 Tomer Blumkin and Efraim Sadka, Minimum Wage with Optimal Income Taxation, February 2004

1126 David Parker, The UK's Privatisation Experiment: The Passage of Time Permits a Sober Assessment, February 2004

1127 Henrik Christoffersen and Martin Paldam, Privatization in Denmark, 1980-2002, February 2004

1128 Gregory S. Amacher, Erkki Koskela and Markku Ollikainen, Deforestation, Production Intensity and Land Use under Insecure Property Rights, February 2004

1129 Yin-Wong Cheung, Javier Gardeazabal, and Jesús Vázquez, Exchange Rate Dynamics: Where is the Saddle Path?, February 2004

1130 Alberto Alesina and Guido Tabellini, Bureaucrats or Politicians?, February 2004

1131 Gregory S. Amacher, Erkki Koskela, and Markku Ollikainen, Socially Optimal Royalty Design and Illegal Logging under Alternative Penalty Schemes, February 2004

1132 David M. Newbery, Privatising Network Industries, February 2004

1133 Charles Yuji Horioka, The Stagnation of Household Consumption in Japan, February 2004

1134 Eiji Fujii, Exchange Rate Pass-Through in the Deflationary Japan: How Effective is the Yen's Depreciation for Fighting Deflation?, February 2004

1135 Mark M. Spiegel and Nobuyoshi Yamori, Determinants of Voluntary Bank Disclosure: Evidence from Japanese Shinkin Banks, Febrary 2004

1136 Robert Dekle and Kenneth Kletzer, Deposit Insurance, Regulatory Forbearance and Economic Growth: Implications for the Japanese Banking Crisis, February 2004

1137 Takatoshi Ito and Kimie Harada, Bank Fragility in Japan, 1995-2003, February 2004

1138 Kunio Okina and Shigenori Shiratsuka, Policy Duration Effect under Zero Interest Rates: An Application of Wavelet Analysis, February 2004

1139 Francine D. Blau and Lawrence M. Kahn, Do Cognitive Test Scores Explain Higher U.S. Wage Inequality?, February 2004 
1140 Michael Rauscher, Economic Growth and Tax-Competing Leviathans, February 2004

1141 Ernst Fehr and Jean-Robert Tyran, Money Illusion and Coordination Failure, February 2004

1142 Ingo Vogelsang, Network Utilities in the U.S. - Sector Reforms without Privatization, March 2004

1143 Marc-Andreas Muendler, Estimating Production Functions When Productivity Change is Endogenous, March 2004

1144 Sascha O. Becker, Samuel Bentolila, Ana Fernandes, and Andrea Ichino, Job Insecurity and Children's Emancipation, March 2004

1145 Pascalis Raimondos-Møller and Alan D. Woodland, Non-Preferential Trading Clubs, March 2004

1146 Robert Fenge and Matthias Wrede, EU Regional Policy: Vertical Fiscal Externalities and Matching Grants, March 2004

1147 Chi-Yung Ng and John Whalley, Geographical Extension of Free Trade Zones as Trade Liberalization: A Numerical Simulation Approach, March 2004

1148 Marc-Andreas Muendler, Trade, Technology, and Productivity: A Study of Brazilian Manufacturers, 1986-1998, March 2004

1149 Eugene Beaulieu, Vivek H. Dehejia, and Hazrat-Omar Zakhilwal, International Trade, Labour Turnover, and the Wage Premium: Testing the Bhagwati-Dehejia Hypothesis for Canada, March 2004

1150 Giorgio Brunello and Francesca Gambarotto, Agglomeration Effects on EmployerProvided Training: Evidence from the UK, March 2004

1151 S. Brock Blomberg, Gregory D. Hess, and Athanasios Orphanides, The Macroeconomic Consequences of Terrorism, March 2004

1152 Bodo Sturm and Joachim Weimann, Unilateral Emissions Abatement: An Experiment, March 2004

1153 Wolfgang Ochel, Welfare-to-Work Experiences with Specific Work-First Programmes in Selected Countries, March 2004

1154 Jan K. Brueckner and Eric Pels, European Airline Mergers, Alliance Consolidation, and Consumer Welfare, March 2004

1155 Aaron Tornell, Frank Westermann, and Lorenza Martínez, NAFTA and Mexico's Economic Performance, March 2004

1156 George Economides, Sarantis Kalyvitis, and Apostolis Philippopoulos, Do Foreign Aid Transfers Distort Incentives and Hurt Growth? Theory and Evidence from 75 Aid-recipient Countries, March 2004 
1157 Robert Fenge and Volker Meier, Are Family Allowances and Fertility-related pensions Siamese Twins?, March 2004

1158 Bruno S. Frey, Simon Luechinger, and Alois Stutzer, Valuing Public Goods: The Life Satisfation Approach, March 2004

1159 Jerome L. Stein and Guay C. Lim, Asian Crises: Theory, Evidence, Warning-Signals, March 2004

1160 Romain Ranciere, Aaron Tornell, and Frank Westermann, Crises and Growth: A ReEvaluation, March 2004

1161 Assaf Razin and Efraim Sadka, Transparency, Specialization and FDI, March 2004

1162 Ludger Woessmann, How Equal Are Educational Opportunities? Family Background and Student Achievement in Europe and the United States, March 2004

1163 B.M.S. van Praag and Barbara E. Baarsma, Using Happiness Surveys to Value Intangibles: The Case of Airport Noise, March 2004

1164 Aaron Tornell, Frank Westermann, and Lorenza Martínez, The Positive Link Between Financial Liberalization, Growth, and Crises, March 2004

1165 Helge Berger and Carsten Hefeker, One Country, One Vote? Labor Market Structure and Voting Rights in the ECB, March 2004

1166 Clemens Fuest and Martin Kolmar, A Theory of User-Fee Competition, March 2004

1167 Friedrich Schneider and Robert Klinglmair, Shadow Economies around the World: What Do We Know?, April 2004

1168 Horst Raff and Nicolas Schmitt, Exclusive Dealing and Common Agency in International Markets, April 2004

1169 M. Hashem Pesaran and Allan Timmermann, Real Time Econometrics, April 2004

1170 Sean D. Barrett, Privatisation in Ireland, April 2004

1171 V. Anton Muscatelli, Patrizio Tirelli and Carmine Trecroci, Can Fiscal Policy Help Macroeconomic Stabilisation? Evidence from a New Keynesian Model with Liquidity Constraints, April 2004

1172 Bernd Huber and Marco Runkel, Tax Competition, Excludable Public Goods and User Charges, April 2004

1173 John McMillan and Pablo Zoido, How to Subvert Democracy: Montesinos in Peru, April 2004

1174 Theo Eicher and Jong Woo Kang, Trade, Foreign Direct Investment or Acquisition: Optimal Entry Modes for Multinationals, April 2004 
1175 Chang Woon Nam and Doina Maria Radulescu, Types of Tax Concessions for Attracting Foreign Direct Investment in Free Economic Zones, April 2004

1176 M. Hashem Pesaran and Andreas Pick, Econometric Issues in the Analysis of Contagion, April 2004

1177 Steinar Holden and Fredrik Wulfsberg, Downward Nominal Wage Rigidity in Europe, April 2004

1178 Stefan Lachenmaier and Ludger Woessmann, Does Innovation Cause Exports? Evidence from Exogenous Innovation Impulses and Obstacles, April 2004

1179 Thiess Buettner and Johannes Rincke, Labor Market Effects of Economic Integration The Impact of Re-Unification in German Border Regions, April 2004

1180 Marko Koethenbuerger, Leviathans, Federal Transfers, and the Cartelization Hypothesis, April 2004

1181 Michael Hoel, Tor Iversen, Tore Nilssen, and Jon Vislie, Genetic Testing and Repulsion from Chance, April 2004

1182 Paul De Grauwe and Gunther Schnabl, Exchange Rate Regimes and Macroeconomic Stability in Central and Eastern Europe, April 2004

1183 Arjan M. Lejour and Ruud A. de Mooij, Turkish Delight - Does Turkey's accession to the EU bring economic benefits?, May 2004

1184 Anzelika Zaiceva, Implications of EU Accession for International Migration: An Assessment of Potential Migration Pressure, May 2004

1185 Udo Kreickemeier, Fair Wages and Human Capital Accumulation in a Global Economy, May 2004

1186 Jean-Pierre Ponssard, Rent Dissipation in Repeated Entry Games: Some New Results, May 2004

1187 Pablo Arocena, Privatisation Policy in Spain: Stuck Between Liberalisation and the Protection of Nationals' Interests, May 2004

1188 Günter Knieps, Privatisation of Network Industries in Germany: A Disaggregated Approach, May 2004

1189 Robert J. Gary-Bobo and Alain Trannoy, Efficient Tuition Fees, Examinations, and Subsidies, May 2004

1190 Saku Aura and Gregory D. Hess, What's in a Name?, May 2004

1191 Sjur Didrik Flåm and Yuri Ermoliev, Investment Uncertainty, and Production Games, May 2004 